\title{
Do álbum de família ao álbum afetivo: as narrativas da memória que transitam entre a fotografia analógica e a digital
}

\author{
Mariana Ferraz Musse ${ }^{1}$
}

\begin{abstract}
Resumo: O avanço tecnológico e a transição da fotografia analógica para a digital trouxeram mudanças significativas nas formas de narrar as memórias dos sujeitos. As transformações técnicas, ao longo dos anos, acarretaram transformações sociais na forma em que os sujeitos se relacionam com as fotografias, do ato de fotografar ao que representam nas imagens. Essas mudanças também se estenderam para as formas de guardar esses registros nos álbuns, quando, no processo digital, as fotografias e os álbuns perdem sua materialidade. Neste artigo, veremos que a transição dos processos analógico ao digital acarretou mudanças no ato de fotografar, de narrar e de guardar. Faremos uma comparação entre o que classificamos como álbum de família (analógico) e álbum afetivo (digital), levando em consideração as principais diferenças envolvidas neste processo como a própria função da fotografia em si, que deixaria de servir à memória - através do registro de momentos como lembranças - e teria como principal função a de conectar pessoas através das redes sociais.Essa nova função de conectividade é estimulada pelas sociabilidades nas redes sociais e enfatizada por mecanismos de interação nas redes como as marcações de pessoas em fotos, e os usos de hashtags e geolocalização pelos usuários.
\end{abstract}

Palavras chave: Narrativa; Fotografia Analógica; Fotografia Digital; Álbum de Família; Álbum Afetivo.

Abstract: The technological progress and the transition from analog photography to digital photography have brought significant changes in the ways of narrating one's memory. The technical changes along the years have caused social transformation in the way one relates to photos, from the act of photographing to what these images represent. These changes have also extended to the ways of keeping these registers in albums, therefore in the digital process photos and albums lose materiality. In this article we shall see that the transition from analog to digital processes resulted in changes in the act of photographing, narrating and keeping. We shall compare what we classify as family album (analog) and affective album (digital), taking into consideration the main differences involved in that process such as the function of photography itself, which would stop serving memory - through the register of moments as keepsakes - and would have as main function connecting people through social networks. This new connectivity function is stimulated by the sociabilities on social networks and emphasized by mechanisms of interaction on the networks such as photo tagging of people, the use of hashtags and geolocation by users.

Keywords: narrative; analog photography; digital photography; Family album; affective album.

1 Doutora em Comunicação pela Universitat Pompeu Fabra (Barcelona, Espanha). Professora da ESPM/RJ e da Universidade Estácio de Sá, no Rio de Janeiro. E-mail: marianafmusse@gmail.com 


\section{Introdução}

O presente artigo faz parte dos resultados da pesquisa de doutorado da autora na Universitat Pompeu Fabra, na Espanha. Nele, trazemos reflexões acerca das relações entre narrativa fotográfica, transformações tecnológicas e suas consequências nas formas de guardar ou arquivar. Para tratar desses assuntos, dividiremos a fotografia em três eras (retrato, Kodak e digital). Passaremos, então, a entender como a fotografia analógica e o álbum de família se caracterizam e, em seguida, as transições para a fotografia digital e a consequente transformação nas formas de guardar, a partir da utilização das redes sociais como espaço para criar álbuns de fotografia.

Parece-nos interessante a divisão da história da fotografia em três etapas, que encontramos no artigo "From Snapshots to social media" (SARVAS; FROHLICH, 2011) e as características que os autores atribuem para cada uma delas. Destacamos a relevância da era Kodak, porque ela modificou toda a forma de se pensar a fotografia, pois deu a possibilidade dos sujeitos comuns, pela primeira vez, se autorrepresentarem e narrarem suas próprias memórias, podendo guardar através de imagens os momentos que não poderiam ser esquecidos e, portanto, deveria ser fotografada para ser eternizada.

Certamente, enquanto o ato de fotografar se limitou aos fotógrafos profissionais, não havia essa necessidade de registrar "cada bom momento vivido"; essa necessidade foi criada pelo mercado, em especial pela empresa Kodak (através da venda de câmeras a preços acessíveis e investimento em publicidade), e acabou se tornando um hábito na vida das famílias. Ao falar das eras da fotografia, também chamamos a atenção para como o aperfeiçoamento da tecnologia das máquinas de fotografar, ao longo do tempo, foi responsável por modificar o uso social que fazemos da fotografia e como nos relacionamos com as imagens nos dias de hoje. A câmera fotográfica foi tornando-se cada vez mais compacta e fácil de ser transportada. Os rolos de filme, por sua vez, foram sendo aprimorados para captar uma imagem cada vez mais nítida.

A era do retrato é compreendida entre os anos de 1839 até 1888 . Nessa fase, o saber sobre a técnica da fotografia ficava nas mãos dos fotógrafos responsáveis por fazer, em sua grande maioria, fotografias de famílias e de casamentos - eles eram conhecidos como retratistas e artistas. O fotógrafo detinha o saber técnico sobre o funcionamento da câmera e sobre o processo de revelação das fotos. O olhar sobre a família ou sobre os eventos fotografados era dado pelo profissional, que utilizava a técnica que dominava para seguir os padrões estéticos de representação deste período.

A era Kodak vai de 1888 a 1990. Ela pode ser compreendida como um gran- 
de momento de transformação para a fotografia. Primeiro, porque a empresa criou câmeras mais baratas e de mais fácil manuseio para que fossem consumidas por pessoas comuns, segundo, porque a possibilidade de que não só os profissionais fotografassem, trouxe um novo significado para a fotografia, muito mais próximo do universo íntimo e afetivo daquele que fotografava. É curioso como a Kodak, através do slogan "Você aperta o botão, nós fazemos o resto" (tradução da autora) [1] simplifica o ato fotográfico a "apenas um click".

A fotografia passou a ser um complexo processo químico que se popularizou como uma prática social cotidiana para milhões de pessoa em todo o mundo que, de repente, sentiram a necessidade de conservar suas recordações, registrando "momentos Kodak" das suas vidas. Durante as férias, casamentos, aniversários, ou simplesmente no lar as câmeras tornaram-se onipresentes. (PHILLIPS, 2013, p. 34, tradução autora). [2]

A era digital começa nos anos 1990 e segue até a atualidade e nos leva de volta ao momento em que a instantaneidade e a possibilidade de armazenar fotos e vê-las no próprio visor da câmera e celulares acabam fazendo com que os antigos rolos de filmes e as câmeras analógicas fossem pouco a pouco perdendo espaço no mercado e sendo substituídas pelas novas tecnologias do universo digital.

A combinação da fotografia digital com a internet está lançando novas possibilidades de usos da imagem. As coisas ainda podem mudar nesse sentido, mas a internet viabilizou o acesso a qualquer tipo de imagem e tornou a circulação das fotografias relativamente fácil para grupos de indivíduos de forma inovadora e questionadora, o que, anteriormente, não era possível, pois elas não estavam disponíveis ou eram difíceis de serem acessadas. (EDWARDS, 2006, p. 135, tradução da autora). [3]

Vimo-nos, então, obrigados a entender mais sobre pixels, dados, cabos e softwares. Curiosamente também, em busca de uma fotografia ideal aos nossos olhos, começamos a dedicar mais tempo ao tratamento da imagem, o que é chamado de pós-produção, edição, tratamento ou manipulação da imagem.

Talvez o mais recente avanço tecnológico e que mais tenha modificado nossa forma de nos relacionar com a fotografia foi a possibilidade de tirar fotos com o celular. A primeira cameraphone comercializada chamava-se Sharp J-SHo4 e começou a ser vendida no Japão, no final dos anos 2000. Outros modelos foram sendo desenvolvidos, até que chegamos ao ano de 2007, quando a Apple lança o primeiro iPhone, que modificou o conceito de aparelhos móveis, pois, através desse aparelho, o smartphone,tanto nossa forma de nos relacionarmos com a realidade foi modificada, como também a forma de narrar a realidade, pois, a partir daí, tínhamos todas as possibilidades em 
mãos: internet, aplicativos, câmera, redes sociais. Assim, todo o processo fotográfico contemporâneo do click ao compartilhamento da foto passou a ser feito a partir de um único dispositivo, em uma velocidade impressionante.

Há uma grande transformação acontecendo atualmente, no âmbito da fotografia doméstica e pessoal, quando acontece um conflito de gerações, que interpretam e vivenciam de forma distinta o uso da fotografia: aqueles que ainda vivem e veem a fotografia como a imagem do "momento Kodak", que deve ser registrado para ficar na memória, e uma nova geração, que tira fotos para se comunicar e conectar com outros indivíduos e não necessariamente com a finalidade de registrar o momento para a posteridade.

A facilidade e a rapidez com as quais as fotos hoje podem ser tiradas e passadas adiante modificam completamente o cenário da fotografia contemporânea e inclusive sua função social. Percebemos nesta discussão que as "três eras" da fotografia foram evoluindo até que se chegasse na contemporaneidade, em que cada indivíduo tem autonomia e condições de ser o narrador/fotógrafo de si mesmo e de sua própria vida. A fotografia hoje passa a ter uma conotação muito similar da que tinha o texto para o diário íntimo. Ela passa a representar o registro pessoal que fazemos do cotidiano, a narrativa de nossos pequenos e grandes momentos, porém, não queremos que fique guardada a sete chaves e, sim, que seja vista pelo máximo possível de pessoas a fim de narrar seu cotidiano.

\section{O álbum de família}

O álbum de fotos por muito tempo foi objeto comum nas mais diversas famílias, cultivado e montado com muito esmero por algum membro, que dedicava seu tempo a guardar essas lembranças de momentos vividos em conjunto para a eternidade. O álbum, enquanto objeto, serve como uma espécie de livro de memórias e até mesmo um livro autobiográfico, que ajuda a narrar determinados acontecimentos vividos por aquele grupo de indivíduos que constituem uma família.

O álbum era montado por alguém que criava alguma lógica narrativa para aquelas imagens, fosse aproximando as fotos por ordem cronológica (por exemplo, um álbum sobre as férias e todos os lugares pelos quais a família viajou na ordem dos dias ou cidades por onde se passou), por evento (aniversário de fulano, casamento de sicrano) ou mesmo um álbum que mostrasse como foi determinado ano para a família 
com os registros mensais.

Sendo assim, além das fotografias em papel, era muito comum encontrar anotações próximas às fotografias, fossem elas fazendo referência à data em que a foto foi tirada, ao nome das pessoas que apareciam na imagem, e ao lugar onde a foto foi clicada. Isso reforça a ideia de que o álbum de família servia como um objeto de memória, que deveria ter o máximo de informações possíveis sobre determinado momento para que "o instante feliz" não caísse no esquecimento e pudesse ser rememorado em detalhes.

O álbum de família é um sistema de arquivo (doméstico) seletivo (como todos os arquivos), e talvez o mais subjetivo de todos. Ele nos permite reorganizar a história - a nossa história - de tal forma que podemos excluir aspectos e momentos que queremos esconder, ou não lembrar, mas também viver, organizar, mostrar, representar, lembrar, reorganizar e reviver em nossas vidas através de nossas próprias regras a partir das imagens que compõem nosso álbum. (VICENTE, 2013, p. 13, tradução da autora). [4]

Silva (1998, p. 19) chama a atenção para uma outra característica interessante ligada ao álbum de família e que ele classifica como uma qualidade grupal do álbum: "alguém narra as histórias, a família, seu narrador coletivo; contudo, outro as conta, em geral a mãe, a avó, a filha mais velha (...) Dessa forma, o álbum não é só visto mas especialmente ouvido".

A partir da evolução tecnológica e da chegada da tecnologia digital, observaremos que até mesmo o local a partir de onde se olham as fotografias (antes, no álbum material, e,depois, no processo digital, em telas de computadores e celulares) interfere na forma do sujeito se relacionar com os registros.

Para Armando Silva (1998, p.24), são três os pré-requisitos para a existência do álbum de família que resultariam no ato de contar, sendo essa a condição narrativa relacionada aos álbuns de família. Os pré-requisitos para essa configuração, segundo o autor, seriam: 1) a família: sujeito representado; 2) a foto: meio visual de registro; 3) o álbum: técnica de arquivo. Observaremos, ao longo da comparação entre o álbum de família e o álbum afetivo, como esses pré-requisitos apontados por Armando Silva vão se comportar em cada um dos tipos de álbuns, a partir das transformações observadas para cada um dos requisitos apontados por ele como fundamentais para a existência do álbum de família e das condições narrativas que ele implica. 


\section{O álbum digital e as novas formas de guardar}

A própria função do álbum de família parece ter sido modificada pelo contexto digital que se apresenta atualmente. Como bem explica Edgar Gómez Cruz:

“O lugar 'natural' da imagem digital já não é o álbum de família, mas estabelece-se por meio das práticas que criam/processam/distribuem através de novos usos, em diferentes ocasiões, funções que são mais de conectividade do que de memória. (CRUZ, 2013, p. 176, tradução da autora). [5]

O autor propõe que, no contexto atual, a função dos álbuns seja mais de conectividade do que de memória. Ainda que no primeiro momento a finalidade do álbum tenha sido modificada pelo contexto digital, a nosso ver, ele continua, mesmo que não seja sua finalidade principal, servindo para armazenar e arquivar fotografias, o que manteria essa função de memória designada aos álbuns de família, havendo, então, apenas um deslocamento na função que deixa de ser exclusiva e principalmente a de memória e passa a ser a de conectividade e a de memória, em um segundo momento.

A chegada da tecnologia digitaltransformou todo o processo fotográfico: desde o momento do click até o tempo de espera para ver o resultado final, além da forma como nos relacionamos com a materialidade da fotografia e sua divulgação nas redes sociais, dando um caráter público a essas imagens. Antes, a maior parte destes registros ficavam restritos ao âmbito privado, da família e amigos próximos.

No princípio da era digital (1990), as fotos eram armazenadas em um cartão de memória com capacidades variáveis e que, toda vez que estivesse com a capacidade esgotada, deveria ter as imagens descarregadas para um computador, onde seriam armazenadas definitivamente ou passadas para um pendrive ou DVD onde ficariam guardadas [6]. Posteriormente, o cartão poderia ser formatado, liberando espaço para que novas fotos fossem tiradas. Essa foi a primeira forma de armazenamentos das fotografias, na era digital, que muito se distingue da limitação e do processo anterior com os rolos de filmes.

Para além das câmeras digitais, devemos falar do processo de armazenamento de fotografias nos smarthphones, que já eliminou do processo, por exemplo, o cartão de memória. As fotos são tiradas e armazenadas na memória do próprio telefone e logo, quando ocupam o limite de espaço, são transferidas diretamente do aparelho para o computador ou para plataformas como a "nuvem" [7], para que possam, em seguida, ser apagadas, dando espaço a novas fotografias. É raro que essas fotos sejam materializadas, como acontecia no processo analógico, apesar de haver aqueles que 
ainda fazem questão de ter as fotografias impressas em papel para evitar que elas, de súbito, desapareçam, caso ocorra algum erro ou problema técnicona leitura dos dados. Atualmente, fotografa-se tanto quando se pode (ou tanto quanto ainda haja espaço para salvar as fotos).

A autorrepresentação a partir da tecnologia digital também é uma auto documentação. Nós não pensamos apenas em como nos apresentar para os outros, mas também em como registrar e documentar momentos das nossas vidas para que sejam lembrados no futuro. (RETTBERG, 2014, p. 11, tradução da autora). [8]

A democratização da internet sem fio, e em especial o surgimento das redes sociais, modificou, mais uma vez, as formas de armazenamento de fotografias e criou outras maneiras de construir álbuns, como veremos. Em relação ao armazenamento, por exemplo, hoje, o usuário pode criar uma conta e ter espaço para utilizar a "nuvem". Essa forma de guardar nossas lembranças, em meio à tecnologia, parece ser uma das mais eficazes da era digital, já que livra o sujeito do "temor" de perder suas lembranças, caso o computador, disco rígido, ou pen drive sofra uma pane, pois tudo estaria "a salvo" no espaço virtual.

É certo que essa transformação na forma de armazenamento da fotografia cria uma nova maneira de se relacionar com as fotos e, como consequência, leva a diferentes usos da imagem, talvez mais instantâneos e efêmeros levando, muitas vezes, a uma desimportância do ato de arquivar esses registros. Isso se dá, pois elas cumpririam sua função de "ser vistas"por outros muito rapidamente a partir do envio de fotos por aplicativos e redes sociais.

A falta de preocupação, que resulta em confiança dos indivíduos na tecnologia, e as atuais formas de "guardar" as fotografias nos levam a pensar também que, de fato, a finalidade da fotografia pode ter sido alterada. São tantas as fotografias tiradas atualmente por cada indivíduo que talvez aquelas que realmente interessam já tenham cumprido seu papel no momento em que são distribuídas nas redes sociais, aquele papel efêmero e momentâneo de registrar o momento vivido e fazer com que a foto seja um meio de conexão com outros indivíduos como comprovação visual de que, de fato, determinada atividade aconteceu e, assim, a fotografia passa a servir, então, como "documento", que comprova a vivência de determinada experiência.

\section{Do álbum de família ao álbum afetivo}

É necessário chamar a atenção para as novas formas de criar álbuns 
na era digital e em especial a partir da chegada da web 2.0 e das redes sociais, que intensificaram ainda mais a finalidade de "conectar-se", que as fotografias ocupam no cenário atual. Para prosseguir, retomaremos então as três condições básicas que enumeramos, de acordo com o pesquisador Armando Silva, para que haja a existência do álbum de família: a família, a foto e o álbum, que resultariam na contação ou na narração dos eventos vividos.

Seguindo e avançando com o modelo de álbum de família, proposto por Armando Silva, para o álbum afetivo, temos de pensar sobre a ação que era vinculada ao álbum de fotografia que era a de "contar" e narrar as fotografias revivendo, relembrando e criando as histórias de cada um dos membros que apareciam nas fotos, transformando-os em verdadeiros personagens, que carregavam consigo histórias, que não deveriam ser esquecidas. Havia a necessidade de uma participação concreta, face à face. Essa função de contar/narrar continua viva na era digital, porém, certamente, também sofreu modificações, em especial, no lugar e na forma em que essa contação acontece. A narração se daria no texto que acompanha a fotografia nas postagens feitas nas redes sociais, ou através da marcação da localização onde a fotografia foi feita, do horário, do uso de hashtags. Além disso, dependendo da forma de envio da fotografia, essa narração poderia se dar por meio de áudios explicando alguma questão relativa à imagem, por exemplo, em um envio feito através do WhatsApp [9].

O álbum, na contemporaneidade, tem uma mudança inclusive nos sujeitos representados nessas imagens, que sugere uma alteração no termo "álbum de família”, uma vez que nem sempre é a família que aparece como objeto central de representação.

Coleções de fotografias instantâneas ou álbuns de família frequentemente apresentam “mapas"genealógicos das famílias. Em um álbum de família, podemos encontrar pessoas de até três gerações daquela família. É comum o álbum ser organizado apresentando crianças, e o responsável por organizar o álbum, próximo a tias, tios, primos e parentes próximos. Não se pode generalizar e dizer que todos os núcleos familiares serão representados simbolicamente na forma da fotografia nestes álbuns. (CHALFEN, 1987, p. 95, tradução da autora). [10]

Atualmente, a temática dessas fotografias foi modificada e acreditamos que isso se tenha dado, em especial, graças ao avanço tecnológico, permitindo que os cidadãos comuns pudessem comprar celulares, que contêm uma câmera fotográfica, e passassem a registrar não só o seu cotidiano, como também a si mesmos. Uma relação mais intimista dos sujeitos consigo mesmos e com seus próximos, chegando mesmo a sugerir críticas negativas a essa exposição da sua própria imagem e intimidade nas redes. A interação desses indivíduos com o espaço público, com a cidade e com os luga- 
res que frequentam foi modificada, pois, agora, eles podem não só registrar, mas, mais que isso, compartilhar com aquele grupo com quem estão conectados(MUSSE, 2017).

Em relação aos sujeitos, que são representados pelas fotos, podemos destacar que as fotos não são mais exclusivas de familiares, mas, sim, de pessoas com as quais dividem-se momentos e experiências. Essa questão da família representada também foi modificada pelas próprias mudanças que o conceito de "família" sofreu na atualidade. Sendo assim, quem é fotografado hoje, não é necessariamente membro da família, mas, sim, indivíduos que são familiares, no sentido afetivo dado à convivência.

A evolução de uma técnica, a fotografia, corre paralela à evolução de uma instituição social, a família, e as novas tecnologias de Imagem desenvolvem-se paralelas às novas formas das pessoas se juntarem familiarmente. A foto passa a ser dado, enquanto o substantivo família se transforma em qualitativo de um modo de ser: a familiaridade. (SILVA, 2008, p. 196).

Destacamos, portanto, a primeira diferenciação que podemos fazer do álbum de família tradicional para o álbum afetivo, como preferimos chamá-lo, uma vez que os sujeitos representados nos álbuns atuais não necessariamente fazem parte da família de quem tem o álbum, mas, sim, são sujeitos com quem este se relaciona afetivamente, nessa nova relação de familiaridade.

O segundo ponto para a existência do álbum seria a foto em si. Nesse sentido, também há algumas diferenças bastante significativas, pois o álbum de família (no sentido trazido neste texto) faz referência ao processo da fotografia analógica e o álbum afetivo utiliza fotografias no processo digital. Apontamos, então, essa primeira diferenciação entre ambas: uma é uma fotografia química, e a outra uma fotografia eletrônica e digital. Essa mudança tecnológica modifica a forma de se relacionar com a fotografia, desde o momento de tirar a fotografia, até o momento de guardá-la. Todo o processo foi afetado pela diferença dos modos de fotografar, na era analógica e na era digital.

O álbum é a outra condição apontada por Armando Silva (2008) como fundamental para que se tenha o álbum de família. Na era digital, o álbum ganha novos formatos e funções em sites de diferentes categorias, alguns deles especializados unicamente em fotografia, como é o caso do Flickr [11] e do Instagram [12] e outras redes sociais como o já extinto Orkut [13] e o Facebook [14], que apresentam espaços para os álbuns, criados pelos usuários.

Podemos apontar uma diferença bastante interessante entre os álbuns de família/materiais e os álbuns de afetos/digitais, para além da diferença em sua função, como já citado. O primeiro, que teria como função primordial manter a memória, e o 
segundo, que teria a função de conectar. No caso do álbum de família, em geral, havia alguém da família que era quem ordenava as fotos, fazia comentários e organizava o álbum. Com a lógica dos álbuns nas redes sociais, cada indivíduo é responsável por criar seu próprio álbum, e fazer uma seleção daquelas fotografias, que deseja que sejam vistas e compartilhadas, não mais tendo a sua própria história contada pela escolha de algum outro membro da família. Cada indivíduo tem o seu próprio álbum, elege as fotos que publicará, e as compartilha com o grupo que for de seu interesse. Sendo assim, a narração de si passa a ser feita pelo próprio sujeito, e não tanto através do "outro", já que ele passa a gerir a própria narrativa de si que é feita, neste caso, através de imagens.

Com as facilidades de armazenamento e exibição disponíveis, os celulares com câmera já têm sido utilizados como álbum de fotografia, e, claro, o compartilhamento, a visualização e as conversas que surgem através desses álbuns de foto são relevantes formas de sociabilidade. (GOGGIN, 2006, p. 2, tradução da autora). [15]

Apresentamos uma tabela que destaca as principais diferenças nas características fundamentais para a existência do álbum de família e do álbum afetivo para uma melhor visualização dos leitores desse artigo, a fim de resumir e destacar o que foi discutido e evidenciado através do texto.

Tabela 1 - Diferenças entre o álbum de família e o álbum afetivo

\begin{tabular}{|c|c|c|}
\hline & ÁLBUM DE FAMÍLIA & ÁLBUM AFETIVO \\
\hline A FAMÍLIA & $\begin{array}{c}\text { • MEMBROS DA FAMÍLIA } \\
\text { • AMIGOS E PARENTES PRÓXIMOS }\end{array}$ & $\begin{array}{c}\cdot \text { INDIVIDUO SOZINHO } \\
\text { • AMIGOS } \\
\text { • PARENTES PRÓXIMOS }\end{array}$ \\
\hline A FOTO & $\begin{array}{l}\text { • QUÍMICA } \\
\text { • MATERIAL } \\
\text { •IMPRESSA }\end{array}$ & $\begin{array}{l}\text { • DIGITAL } \\
\text { • VIRTUAL } \\
\text { • PÓS-PRODUZIDA } \\
\text { • COMPARTILHADA }\end{array}$ \\
\hline O ÁLBUM & $\begin{array}{c}\bullet \text { FEITO PARA } \\
\text { REPRESENTAR UM GRUPO } \\
\bullet \text { PRIVADO } \\
\text { • MEMÓRIA }\end{array}$ & $\begin{array}{c}\text { • FEITO PARA REPRESENTAR A SI } \\
\text { • PÚBLICO (REDES SOCIAIS) } \\
\text { • CONECTIVIDADE }\end{array}$ \\
\hline
\end{tabular}

Fonte: a autora

\section{Considerações finais}

Pensar neste modelo de álbum afetivo/digital é pensar na nova lógica da fotografia, é pensar na incrível rapidez e agilidade com que ela pode ser compartilhada e vista por outros usuários nas redes sociais. Certamente, e mais uma vez, tocamos no 
ponto fundamental para o avanço da tecnologia e das novas formas de sociabilizar, geradas pelas redes sociais e, sem dúvida, devemos nos lembrar que se hoje são carregadas mais de 70 milhões de fotos por dia (INSTAGRAM, 2015) no Instagram, por exemplo, isso ocorre graças à possibilidade de fazer fotos e compartilhá-las rapidamente através da internet.

Observamos algumas diferenças e transformações que o álbum sofreu, através do avanço tecnológico, a transformação da tecnologia analógica para a digital, que modifica a forma do sujeito se relacionar com a câmera, com a foto, com o álbum e até mesmo com as pessoas ao seu redor. Neste sentido, a fotografia, através da facilidade tecnológica para fazer registros, acabou adquirindo uma nova função no mundo contemporâneo. Ela passa a narrar o próprio sujeito em si, em especial através da selfie, tornando-se instrumento para a formação da identidade individual e coletiva de uma geração, através de narrativas que o próprio sujeito constrói e compartilha instantaneamente. Neste sentido, por exemplo, o fotógrafo da cena acaba sendo, simultaneamente, um sujeito que é representado na imagem. Com isso, deixa-se de lado o olhar distante do fotógrafo sobre a cena, porque agora, muitas vezes, ele ocupa as duas posições simultaneamente a de fotógrafo e a de sujeito representado, escolhendo através do seu ponto de vista (observado nos ângulos e enquadramentos preferidos) como vai narrar aquele momento fotografado.

Refletindo sobre o modelo de álbum de família, proposto por Armando Silva, e chegando no modelo do álbum afetivo, destacamos a diferenciação na ação que era vinculada ao álbum de fotografia: a de "contar" e narrar as fotografias. Ao reviver, relembrar e criar as histórias de cada um dos membros que apareciam nas fotos, eles eram transformados em verdadeiros personagens, que carregavam consigo histórias, que não deveriam ser esquecidas. Havia a necessidade de uma participação concreta, face à face para esta rememoração das imagens. Essa função de contar/narrar continua viva na era digital, porém, certamente também sofreu modificações, em especial, no lugar e na forma em que essa contação de histórias acontece.

A foto e o álbum, nos ambientes digitais, geram discussões, comentários e interações entre os indivíduos, porém de maneira diferente. Dificilmente, se vai estar sentado próximo a uma outra pessoa, olhando o álbum, e tecendo comentários a cada nova foto que se vê (mesmo porque, em muitos casos, o número de fotos passa de 500, no álbum digital). Falar sobre cada uma das fotos do álbum digital ou sobre cada pessoa que aparece ali levaria um tempo que hoje poucos têm para isso. A narração, então, se desloca para o ambiente virtual e a explicação sobre a foto será dada por meio da 
legenda das fotos, "marcações" de pessoas e hashtags utilizadas, que darão aos usuários, que acessarem a fotografia, ferramentas suficientes para que façam a interpretação necessária da imagem e compreendam, no ambiente virtual, o significado daquela narrativa.

Podemos dizer que o aprimoramento da tecnologia ao longo dos anos transformou as relações dos sujeitos com a fotografia, enquanto objeto, dando novos sentidos e funções para seu uso. As fotografias são utilizadas para conexão entre pessoas no momento presente e as ferramentas disponíveis em aplicativos e redes sociais colaboram para esse maior uso das imagens para uma rápida e eficiente comunicação instantânea. Aliada a outros recursos que também favorecem a conexão entre pessoas nas redes como, por exemplo, as marcações de geolocalização e pessoas nos posts, e/ouuso de hashtags,alimentam e fortalecem esse uso da fotografia como forma de conectar pessoas. De todo o modo, sabemos que a fotografia, ainda hoje, também fica arquivada nos álbuns criados nessas redes ou no próprio rolo da câmera dos celulares, podendo ser revisitada pelos usuários para relembrar algum momento, quando quiserem. Vemos, inclusive, um incentivo a essa rememoração, através do uso de uma hashtag específica para ser usada, às quintas-feiras, nas redes sociais: a \#tbt (a siglasignifica "Throwback Thursday", e pode ser traduzida do inglês como quinta-feira do retorno ou quinta-feira do regresso). Neste dia, os usuários são incentivados a postarem uma foto antiga seguida da hashtag,rememorando um bom momento vivido no passado. Ou seja, a função de memória continua vinculada à fotografia na era digital, talvez, deixando de ser, na contemporaneidade, apenas a principal delas.

Sendo assim, a narração sobre os fatos, que aparecem nas fotos, continua acontecendo, porém, com um deslocamento da narração para o espaço público, entre pessoas conhecidas e desconhecidas, e marcada pela simultaneidade do compartilhamento da narrativa, que, agora, não necessita nem mais respeitar o tempo entre o registro e a sua divulgação, como também prescinde do contato face à face.

\section{Notas}

[1] "You press the buttom, we do the rest".

[2] [...] la fotografía pasó de ser una complicada operación cuasi alquímica a popularizarse como una práctica social cotidiana para miles de millones de personas de todo el mundo que de repente sintieron la necesidad de conservar los recuerdos registrando los momentos Kodak de sus vidas. En vacaciones, bodas y cumpleaños, o sencillamente en el hogar las cámaras se hicieron omnipresentes. (PHILLIPS, 2013, p. 34).

[3] [...] the combination of digital photography and the internet is opening up new possibilities for the use of images. Things may change in this respect, but at the moment the internet allows 
access to all manner of images and makes it relatively easy for groups or individuals to circulate photographs in innovative and critical ways, which would previously have been unavailable or difficult to view. (EDWARDS, 2006, p.135).

[4] El álbum de familia es un sistema de archive (doméstico) selectivo, como todos los archivos, quizás el más subjetivo de todos. Nos permite reordenar la historia, nuestra historia, de tal forma que podemos eliminar aspectos y momentos que queremos olvidar, o no recordar, pero también vivir, organizar, presentar, representar, recordar, reorganizar y revivir nuestras vidas con nuestras propias reglas a través de las imágenes que componen nuestro álbum . (VICENTE, 2013, p. 13).

[5] "El lugar 'natural' de la imagen digital no es ya el álbum familiar, sino que se constituye, a través de las prácticas que la generan/procesan/distribuyen, con nuevos usos que, en muchas ocasiones, son más de conectividad que de memoria”. (CRUZ, 2013, p. 176).

[6]Este processo continua em uso em muitas câmeras que dependem do cartão de memória para armazenar os arquivos.

[7] Segundo a Microsoft Azure a nuvem é "um termo utilizado para descrever uma rede global de servidores, cada um com uma função única. A nuvem não é uma entidade física, mas uma vasta rede de servidores remotos ao redor do globo que são conectados e operam como um único ecossistema. Estes servidores são responsáveis por armazenar e gerenciar dados, executar aplicativos ou fornecer conteúdos ou serviços, como transmissão de vídeos, webmail, software de produtividade ou mídias sociais. Em vez de acessar arquivos e dados do local ou de um PC, você pode acessá-los online, de qualquer dispositivo com acesso à Internet. As informações estarão disponíveis em qualquer lugar, a qualquer hora”. (MICROSOFT, 2019).

[8] Self-representation with digital technologies is also self-documentation. We think not only about how to present ourselves to others, but also log or record moments of our lives for ourselves to remember them in the future ". (RETTBERG, 2014, p. 11).

[9] Criado em 2009, o WhatsApp é um aplicativo multiplataforma de mensagens instantâneas e chamadas de voz para smartphones. Além de mensagens de texto, os usuários podem enviar imagens, vídeos e documentos em PDF, além de fazer ligações grátis por meio de uma conexão com a internet.

[10] "Snapshot collections and family albums frequently provide visual "maps" of kinship networks. One family album may include three generations of people. An album maker's parents and children will frequently be found together next to aunts, uncles, cousins and fictive relatives. This is not to say that all members of a nuclear or extended family will be present in photographic symbolic form."(CHALFEN, 1987, p. 95).

[11] O Flickr foi criado com a intenção de ser um site de hospedagem e compartilhamento de imagens fotográficas ou gráficas, em 2005. Foi criado, no Canadá, e hoje pertence ao Yahoo.

[12] O Instagram é uma rede social, que foi lançada em 2010, com o formato de aplicativos para celular que, a princípio, apenas compartilhava fotos, mas, hoje, também aceita o compartilhamento de vídeos de até 15 segundos. O aplicativo foi comprado pelo Facebook, em 2012.

[13] O Orkut foi uma rede social criada em 2004 e extinta em 2014; essa rede social era filiada ao Google.

[14] O Facebook foi uma rede social fundada em 2004, que atua até hoje, e que já extrapolou a função única de rede social, servindo como espaço para bate-papo, fazer ligações, espaço publicitário, entre outros.

[15] "With the storage and display facilities available, camera phones are already being used as a photo album, and of course the sharing, showing and talk around photo albums are an important form of sociality."(GOGGING, 2006, p.2). 


\section{Referências}

BARBOSA, Visa Mariona. Evolució sociológica i narrativa de l'álbum fotogràfic familiar:anàlisi pragmática de l'álbum familiar analògic i digital des dels anys seixanta fins a la primera década del segle XXI. Disponível em: < http://hdl.handle. net/10803/81080 > Acesso: 18.fev.2017.

CHALFEN, Richard. Snapshot versions of life. Madison: University of Wisconsin Press, 1987.

CRUZ, Gómez Edgar. Mas allá del álbum fotográfico: (des) materializaciones y memoria en la fotografia digital. In: VICENTE, Pedro (Ed).Álbum de família:representácion, recreácion y inmaterialidade de las fotografias familiares. Madrid: Oficina de Arte y Ediciones, 2013.

EDWARDS, Steve. Photography: avery short introduction. Oxford: Oxford University Press, 2006.

GOGGIN, Gerard. Cell phone culture: mobile technology in everyday life. New York: Routledge, 2006.

INSTAGRAM. Disponível em: <https://instagram.com/press/> Acesso: 04.mar.2018.

MICROSOFT, Azure. Disponível em: <https://azure.microsoft.com/pt-br/overview/ what-is-the-cloud/> Acesso: 10.mar.2019

MUSSE, Ferraz Mariana. Narrativas fotográficas no Instagram: autorrepresentação, identidades e novas sociabilidades. Florianópolis: Insular, 2017.

PHILLIPS, Nelson; MUNIR, Kamal. El nacimiento del momento Kodak. In: VICENTE, Pedro (Ed). Álbum de família:representación, recreación e inmaterialidad de las fotografías familiares. Madrid: La Oficina, 2013.

POU, Jordi. Álbum de familia 2.o: socialización de la memoria fotográfica:la era Smartphone/iPhone. In: VICENTE, Pedro (Ed). Álbum de familia: representación, recreación e inmaterialidad de las fotografías familiares.Madrid: La Oficina, 2013.

RETTBERG, Jill Walker. Seeing ourselves through technology:how we use selfies, blogs and wearable devices to see and shape ourselves. Palgrave Macmillan, 2014. Disponível em: <http://jilltxt.net/books/Seeing-Ourselves-Through-Technology-full-book.pdf > Acesso: 15.jul.2017.

RUBINSTEIN, Daniel; SLUIS, Katrina. A life more photographic, Photographies, p. 9-28, 2008.

SARVAS, Rito; FROHLICH, David. From snapshots to social media:the changing picture of domestic photography.Londres: Springer, 2011.

SILVA, Armando. Álbum de família:a imagem de nós mesmos. São Paulo: Editora Senac, 2008. 